\title{
Meaning and Matter in Psychiatry: A Historical View and New Approach
}

\author{
Ketil Slagstad MD \\ PhD Student, Institute of Health and Society, Faculty of Medicine, University of Oslo, Oslo, Norway \& Institut für Geschichte \\ der Medizin und Ethik in der Medizin, Charité Universitätsmedizin Berlin, Berlin, Germany
}

\begin{abstract}
In this article, I argue that a person-centered approach in psychiatry needs to pay attention to how mental illnesses are historically constituted and products of biological, social, psychological and cultural factors. Even if the ambition of the biopsychosocial model and the medical network model was to break with reductionist understandings of (mental) illness, I argue that these models risk stabilising, rather than deconstructing dichotomies between nature versus culture, brain versus mind, somatic versus mental or hard facts versus soft sciences. I rather propose to re-orient psychiatry as a form of "relational medicine" in which causes and reasons are treated as inseparable and where matter and meaning are entangled. A person-centered approach in psychiatry must start with the person including the embodied production of meaning in Society.
\end{abstract}

\section{Keywords}

Biopsychosocial model, diagnostic classification, epistemology, network model, reductionism

\section{Correspondence address}

Dr. Ketil Slagstad. E-mail: ketil.slagstad@medisin.uio.no

Accepted for publication: 17 November 2019

\section{Introduction}

In the history of modern Euro-American medicine two opposing views of how we best can understand diseases and what to do about them have been dominant. On the one hand are reductionist approaches, where a major objective has been to describe disease mechanisms in finer detail. On the other hand are those who have claimed that an understanding of diseases will always be incomplete if we leave the sick person out of our account [1-3].

Modern Euro-American medicine, or biomedicine, is of course not one model, rooted in one epistemology or characterised by one practice. Too many sociological critiques have been based on an unnuanced and "strawman" representation of biomedicine as reductionist [4]. In the history of Euro-American psychiatry, specific epistemological challenges have evoked different historical and local responses. However, it still makes sense to trace the history of two main positions that are partly complementary, partly opposing. The 20th century witnessed a diversification of methodological traditions in psychiatry into, among others, psychoanalysis, biological psychiatry, and social psychiatry. Since the birth of the discipline, many academic psychiatrists have had the ambition of rooting it in biology, making psychiatry a true biomedical profession. At the end of the $20^{\text {th }}$ and beginning of the $21^{\text {st }}$ century the prospects for this looked bright, given major scientific achievements such as the sequencing of the human genome (the Human Genome Project), new techniques for the visualisation of the brain, and the identification of molecular mechanisms involved in psychiatric illness. Genetic and neurobiological findings, however, have not led to any major breakthroughs in diagnostics or the treatment of mental illness. In spite of a considerable amount of findings of genetic associations in mental illness, it has been hard to translate these insights into etiological models [5-8].

This current situation represents a good opportunity to take a step back and analyse the developments thus far. Current biomedical psychiatric models for understanding mental illness and diagnostic manuals draw on an epistemological heritage which goes back to the $19^{\text {th }}$ Century. This genealogy coalesces with the historical idea of mental illnesses as natural objects or things in the world, where a major ambition of the profession has been to identify and delineate disease entities. This ambition has come at a price, namely dualist views on human suffering: nature versus culture, brain versus mind, somatic versus mental. These dichotomies were enforced through different historical developments, and an operational psychiatric language and diagnostic manual has cemented them.

This paper argues that history, culture, nature and Society play active and constitutive roles not only in our understanding of mental illnesses, but also in their materialities. A new epistemology for psychiatry needs to 
incorporate biomedical findings with insights from social science and the humanities, such as history, hermeneutics, phenomenology, anthropology, STS-studies and feminist theory. A starting point for this epistemology is a truly person-centred approach, where causes and reasons, explanations and understandings are seen as inseparable. Modern medicine is becoming more and more specialised. This process of subspecialisation has undoubtedly brought major advancements in the understanding of disease mechanisms and has led to new treatments. But splitting medicine into smaller and smaller niches has also made transdisciplinary integrative theorisation harder. I will argue that real progress in the field of mental health depends on approaches that cross the lines dividing traditional fields.

This chapter begins with a short overview of the genealogy of dualism in modern psychiatry and argues that dualism has its historical roots in biological psychiatry and an operationalist diagnostic system. It then turns towards hermeneutics and phenomenology and argues that in psychiatric epistemology causes and reasons cannot be separated. It concludes with a sketch for a new epistemology for psychiatry. Obviously, it would be hubris to proclaim that this paper could provide a definitive new epistemology of psychiatry. It should instead be read as an attempt to problematise certain points I see as major hurdles in the development in the field. I will highlight ideas and thoughts that, I contend, have been easily forgotten in a field that has, to an increasing degree, become dominated by technological advancements and neurobiological findings. A major argument of the chapter is that meaning and matter are entangled, and that this insight should serve as the founding basis for a theoretical reorientation in psychiatry.

\section{Dualism and the biopsychosocial model}

Most psychiatrists working in a Euro-American medical tradition would claim that they adhere to a biopsychosocial model as opposed to a strict biomedical approach in their work. The biopsychosocial model was proposed at the end of the 1970s as a challenge to a medicine that had become increasingly reductionist. Diseases, it argued, needed to be seen as products of biological, psychological and social factors [9]. Distinguishing between disease (referring to the biomedical definition of pathology), illness (to the subjective experience) and sickness (to the societal and functional consequences), has further added to our realisation that a purely biomedical-pathological definition of disease in general and, more specifically, in mental health, would miss important aspects of what it means to be sick and what to do about it [10,11].

Empirical-based pluralism has been proposed as a refinement of the biopsychosocial model for psychiatry [8]. According to this model, etiological factors in mental illness can be categorised as biological, psychological, and "higher-order" which are then further subcategorized. The biological factors are subdivided into for instance molecular genetics, neuroscience and aggregate genetic effects; the psychological factors into neuropsychology, personality and trauma; and ultimately the higher-order into social (e.g., drug use, urbanization), political factors (e.g., alcohol taxes) and cultural factors (e.g., help-seeking behaviour). This model, according to Kenneth S. Kendler, differs from the biopsychosocial model by not having a programmatic precondition - ideology - for seeking or explaining mental illnesses in multifactorial terms. Empirical-based pluralism is atheoretical, designed to be flexible and driven by research: empirical findings explain aetiology.

Both the biopsychosocial model and empirical-based pluralism explicitly try to break with reductionist understandings of mental illness. But computer technology has given dualistic thoughts new life and a new language: the brain is hardware, the mind is software, and mental illnesses are either hardware problems (organic) or software problems (functional) [8]. Kendler claims that even though most of his psychiatrist colleagues would reject a dualist view on mental illnesses and would claim they work eclectically in their choice of therapy and regard mental illnesses as multifactorial, "their actions belie their words" [8]. In the diagnostic manuals, the term "mental" is still in the title, and even if the term only makes reference to the psychological experience in the individual (feeling sad, depressed, panic attacks etc.), it still has etiological connotations. In other words, mental is the opposite of physical, as the mind is of the brain and the functional of the organic. Why is that? Is it possible to trace a specific genealogy of the dualistic paradigm in the history of psychiatry? Two developments have been crucial: first, a biologically inspired research tradition and its epistemological axiom that mental illnesses are natural objects, and second, an operational diagnostic tradition.

\section{Three waves of biological psychiatry}

If we look at the history from a bird's-eye perspective, we can discern three epochs of biological influence on EuroAmerican psychiatry [12]. Madness was taken up by European medicine at the end of the $18^{\text {th }}$ and beginning of the $19^{\text {th }}$ Centuries. This is often seen as the birth of modern psychiatry. Gradually, doctors turned madness into a medical object. To a large extent, it was social, economic and normative demands and views rather than empirical facts that laid the ground for what was regarded as mental illness [13,14]. In neurology, clinical observation and pathological dissection were inseparable practices that informed one another. Psychiatrists tried to apply this anatomo-clinical model to mental illnesses. Their objective was to identify anatomical substrates that caused the symptoms of the patients. German psychiatrists developed and refined the model in the second half of the $19^{\text {th }}$ century: 'Mental diseases are diseases of the brain', proclaimed Wilhelm Griesinger (1817-1968), the founding 
father of German university psychiatry. This was the first wave in the biological psychiatric paradigm.

The second wave hit psychiatry around the mid $20^{\text {th }}$ Century. American and European psychiatry changed radically in the decades after the Second World War. The structure of DNA was discovered and genetics offered hope that new insights into the aetiologies of psychiatric illnesses would be discovered. Within a decade, there was a significant breakthrough in psychopharmacology. Major groups of psychiatric medicines entered the market lithium (1949), chlorpromazine (1952), imipramine (1957), haloperidol (1958), diazepam (1963) - and raised hopes of finding a cure for psychiatric illnesses and revolutionising care. Historians of science and medicine have shown how drugs themselves have played active epistemological roles in producing our understandings of diseases and diagnostic concepts. For instance, lipid-lowering drugs and hypertensives helped establish the diagnoses of hypercholesterolemia and hypertension, respectively [15]. In psychiatry, neuroleptics (later renamed antipsychotics) supported simplistic models of schizophrenia as a disease of dopamine over-activity [16,17]. A second wave of biological thinking hit psychiatry.

We are currently in the midst of a third wave of biological psychiatry which emerged towards the end of the $20^{\text {th }}$ Century [12]. This development is driven by technological progress in neuroradiology, for example, functional-MRI and big-data calculations in neuroscience and genetics, and by insights into molecular mechanisms and epigenetics. Increasingly, mental illnesses are understood as dysfunctions in brain networks (connectivity). Research is not only focused on neurotransmitters, but also on the up- and down-regulation of cell receptors, intracellular cascades and neuron regeneration. New journals are dedicated to molecular psychiatry, for instance "Molecular Psychiatry" [18]. Mental illnesses are conceptualised as multi-organ, systemic illnesses involving a myriad of intra- and extracellular mechanisms $[19,20]$. The ambition to identify causal mechanisms connecting symptoms or syndromes with a neurobiological substrate remains central to the paradigm we are currently experiencing.

\section{Diagnostic systems}

Let us now turn to what I will argue is the other driving factor in a dualist ontology. How do we describe what we see? It depends on how we understand what we see, though what we see is also inseparable from how we describe it. The current diagnostic manuals are often regarded as atheoretical and purely descriptive. Do they catch the essence of the phenomenon they aspire to describe?

When the Diagnostic and Statistical Manual of Mental Disorders (DSM) underwent a radical shift in the 1970s, it had a profound impact on psychiatric thinking and practice. Psychoanalysis played a big role in post-war US psychiatry, partly because of the many European psychoanalysts who had fled the war. Various developments and incidents led to a surge of biological understandings and practices in psychiatry (for instance psychopharmaceuticals as mentioned above), but psychoanalysis was increasingly criticised for being unscientific. Its diagnostic criteria lacked reliability. Towards the end of the 60s, several international projects by the WHO showed that European and American psychiatrists could not agree upon diagnostic criteria. American psychiatrists, for instance, diagnosed patients with schizophrenia more often than they did with affective psychosis compared to their European colleagues. In the famous Rosenhan-experiment, eight healthy people showed up at different mental hospitals and pretended that they were hearing voices. Everyone was admitted, and even though they behaved normally and denied hearing voices during the stay, they were all discharged with the diagnosis of "schizophrenia in remission" [21]. Obviously, this was not worthy of a modern profession. Potent drugs gave psychiatrists radical new measures to treat mental illnesses, but they needed to know what they were treating.

That was part of the backdrop for the dramatic change in the diagnostic system that occurred between a psychoanalytically inspired DSM I and II and the "atheoretical" DSM III and later editions. The diagnoses became descriptive, criteria-based and categorised. The psychiatric language changed to a "neutral" one, descriptions stripped of interpretation and context. This can be defined as psychiatry's operational turn [21]. The phenomenological-diagnostic tradition was more solidly rooted in Europe, especially in Germany, but soon the need for a common diagnostic system across the continents became pressing. When WHO launched ICD-10 in 1992, it followed the same diagnostic principles as in DSM III.

It is often claimed that without diagnoses we walk in darkness. Many would claim that the diagnostic manuals are only meant to be guides, and that how we understand the illnesses is a different question. And which reality, anyway, are we describing? If you follow the diagnostic criteria for depression in DSM V then there are 1,497 different combinations for the diagnosis [21]. The criteriabased system forces the clinician to diagnose several illnesses in the same individual (comorbidity), since the clinical picture does not fit the criteria for one diagnosis. The widespread use of the diagnosis of "not otherwise specified" and the arbitrarily defined limitations between healthy and ill - depending on the quantifiable number of symptoms - are all considered serious methodological problems within the classificatory system itself. These problems raise questions about the validity of the diagnostic system [22]. To use a comparison: when you hike in the mountains, is it better to use a defective compass than no compass at all?

\section{The need of a new approach}

Biological psychiatry, and an operational diagnostic system, take for given that mental illnesses are stable, identifiable and circumscribable entities in nature [23]. The biopsychosocial model seeks to integrate biological findings in mental illness with psychological and social insights. The model encourages us not to forget that 
illnesses have multifactorial causes. The model thus makes sense on a group level, since risk factors are divided into biological, psychological and social categories. But it can also be applied to an individual case. It can, for instance, help explain why mental illness develops in a person with increased genetic risk (family history), because of social factors (for instance, drug use) or psychological experiences (for example, losses, abuse).

However, it is easy to conjoin three words in theory, but much more difficult to turn the theory into practical tools [24]. The biopsychosocial model has strengthened the dichotomy in which "bio" equals hard facts and "psychosocial” equals the soft sciences [3]. The model also lacks a critical perspective on illnesses as historically, socially and politically constituted. The biopsychosocial model is theoretically hollow. It does not provide tools for understanding how "nature" and "culture", the individual and Society, matter and meaning are entangled. Symptoms and clinical signs have been moulded, held together and constituted as natural objects - as matter - differently through history. The neurobiological substrate is the glue which has held the symptoms and diseases together [14]. But in an anatomo-clinical model of disease, psychological, phenomenological understandings and descriptions of mental processes are only imprecise, hazy approximations of a reality which can be pinned down on neural or molecular levels [25]. Symptoms are just epiphenomena of a founding, identifiable neurobiological substrate.

New conceptualisations of the causes of mental illness explicitly challenge reductionist assumptions. According to network theory or network approaches to mental illness, symptoms and signs are not merely reflections of underlying neurobiological substrates, but causal factors themselves [26-28]. Symptoms and signs interact on different levels and are reinforced in feedback loops which themselves constitute the illnesses. The approach of mapping the networks on different levels, integrating the 'omics' (genomics, proteomics, connectomics etc.) with psychological and societal factors in multilayer diagrams, is intrinsically anti-reductionist and should be welcomed. The model, however, runs the risk of turning into what Josef Parnas has labelled a 'psychiatry without psyche' in another context [29]. Even though the model is, in theory, open for multilevel analysis and open to empirical input from several disciplines, the individual-level brain disease model tends to dominate.

I will now outline a sketch for a different approach to psychiatric epistemology. This sketch does not aspire to be all-encompassing or fulfilling, but should rather be regarded as an attempt to problematise what I see as blind spots in current biomedical psychiatric epistemology. I fear that a reductionist or essentialising biological approach to mental illness runs the danger of ignoring insights from other disciplines crucial to identifying why people get sick and how we can best help people. A new approach should aspire to be truly transdisciplinary, and borrow tools from the humanities and social science.

\section{Hermeneutics, horizons and epistemic injustice}

If the technological advancements in neurobiological research make us capable of fully pinning the causes of mental illnesses, would that render a theory of subjectivity or a person-centred understanding of the patient superfluous? Can natural science and its methods provide access to the subjective?

Medicine and psychiatry are about treating people, not diagnoses. However, in psychiatry the helper faces some challenges that differ from general medicine. In psychiatry, the conversation is both the main diagnostic tool and a major therapeutic instrument. Even though the conversation is of crucial importance in all parts of medicine, in other specialities other diagnostic tools are often available to provide definite answers. In the mental health field, the helper to a big degree needs to make decisions based on what she or he sees or hears. Interpretation depends on knowledge, experience, background and sociocultural factors, among others. Psychiatry is a field where interpretation plays a decisive role. And psychiatry might be especially prone to letting structural discrimination and prejudices affect how phenomena are interpreted and handled.

Hermeneutics has taught us that knowledge about Man - from either texts or conversation - is characterised by a fusion of horizons: one's own and the horizon of the subjective object that one is encountering. Understanding is a process where one's own prejudices are "tested" against the understandings of the other. Knowledge depends on a circular process by which one needs to understand each individual part in order to understand the whole, but an understanding of each individual part is established with reference to the whole. Neither the entirety nor the individual parts can be understood without reference to one another. By stepping in and out of this process, from part to whole and back to part, one makes phenomena comprehensible [30,31].

Realising that we always meet, interpret and interact with phenomena via our own limited horizons, is an important hermeneutical insight for psychiatry. But it is also relevant which horizons we bring with us, since marginalised perspectives have been and still often are neglected (for instance the perspectives of women, people of colour, people with disabilities and even the perspectives of the mentally ill). How these horizons influence our understandings and actions in the world, as well as our mistakes, has been deciphered in a nuanced manner by Miranda Fricker [32]. She points to the ways a speaker can be wronged when the listener does not listen to, believe, or appreciate the perspective of the speaker owing to prejudice on part of the listener. Devaluating the perspectives of a person of colour or a Muslim because they are non-white or non-Christian, or the perspectives of a person with a mental illness because she or he is mentally ill, are examples of this discrimination. These are examples of what Fricker defines as "testimonial injustice". On the 
other hand, she defines "hermeneutical injustice" as a kind of structural injustice where experiences and phenomena are rendered unintelligible for others and even for the person having them because of hegemonic views and understandings. The person is thus restricted in her or his process of understanding and of articulating herself or himself or her or his experiences. What implications does this insight have for how we think about causality?

\section{Causalities}

We are used to thinking that causes and reasons are different phenomena. Causes - or explanations - belong to science; reasons - or understandings - belong to social science and the humanities. The first is hard and objective, the latter soft and subjective. A major goal in science is finding objective truths and causalities. Causal explanations are often regarded as closer to truth and more scientific than meaning-seeking knowledge. The latter is often regarded as unscientific, irrational or an example of subjectivism [33]. Often, in the health sciences, it is assumed that causal relationships can only be established through observational studies or randomised controlled trials. However, the causality that is identified in these kinds of studies is actually an observed series of regular events supported by counterfactual evidence (the absence of an observation in a control group establishes the observed causality in the study) [34]. A dispositional account of causation on the other hand acknowledges that in biology there very seldom are simple relationships between cause and effect. Most such relationships are complex. Therefore, it is more accurate to talk about dispositions and tendencies towards outcomes when examining causes. A dispositional account of causality dissolves the problem of induction - even though past events occur regularly, we cannot draw firm conclusions about future regularities: causations are tendencies towards outcomes [34].

Taking this insight seriously has implications for how we do research and what kind of research we appreciate. Even though randomised controlled trials and epidemiologic studies are crucial to medicine, they might have led us to ignore other kinds of knowledge, for instance from social science, anthropology and history. A central ambition of evidence-based medicine has been to identify objective causal relationships about health, illness and treatment. Methods like blinding or the usage of comparable control groups makes it possible for the data itself to speak. The perspective of the individual or the researcher is left out, and thus bias could be eliminated. But the same methods have also eliminated the subjective from the object in study [35]. Epidemiologic studies can provide knowledge about statistical regularities and point to causation, but they cannot provide causational explanations in the individual. Case studies approach causation in a more direct way, taking into mind the situatedness and complexity of each individual case. Another way is to bring the patients to the fore. User involvement through the entire research process, from identifying adequate research questions and developing questionnaires to interpreting the results and distributing the findings, could make psychiatric research far more person-centred. It would also compensate for the testimonial injustice paid to the patient perspective in mental health research.

\section{Explanations and understandings}

According to psychiatrist Nancy Andreasen, who was centrally involved in formulating the DSM III, the operationalist turn in psychiatric diagnostics has had serious consequences. Using the DSM as a textbook could mean that psychopathological symptoms or unmentioned signs are overlooked or go unnoticed. According to Andreasen, the diagnostic manual has had a dehumanising impact on psychiatry: ruling checklist-based symptoms in or out discourages the healthcare worker from getting to know the patient as a person. Validity has been sacrificed for the sake of reliability. 'DSM diagnoses have given researchers a common nomenclature - but probably the wrong one' [36].

The development of powerful and sophisticated technology in psychiatric research - such as functional MRI or genome-wide association studies (GWAS) - has been explosive. The development of a psychiatric descriptive language, however, has not kept up. It is meaningless to identify and describe one variable to the last detail if this is to be correlated with phenomenon described in a coarse, unprecise and outdated language [37]. What consequences does that have for research? The research paradigm of trying to identify functional neurological differences among groups of people with mental disorders by using a functional MRI is in danger of confirming its own diagnostic categories. Among patients with depression defined by criteria in diagnostic manuals, for instance, certain brain mechanisms are identified which are characteristic for patients defined by criteria for depression. A stone is a stone because it is a stone. If the description of the symptoms and the diagnostic criteria do not capture the essential parts of the phenomenon - what is characteristic of being mentally ill - we run the risk that the whole foundation for the research is mistaken. That, in turn, makes it hard to translate and transfer the research findings to real life situations.

\section{Not a new problem}

The problem is not new. Around the turn of the $20^{\text {th }}$ Century the psychiatrist and philosopher Karl Jaspers (1883-1969) criticised a narrow biological tendency in German psychiatry. It is a 'brain mythology' to believe that the illnesses could be localised in the brain, he said. For Jaspers, the claim that mental illnesses are diseases of the brain, and that everything mental is only mental, was a sterile position. Except for recognising that everything mental involved the brain and was partly dependent on it, he discarded the claim as meaningless [38]. He rejected reductionist explanations for mental illnesses and instead sought to understand mental disorders in the intersection 
between subjective experience, psychological mechanisms, biological processes and a sociocultural framework [39]. On one hand, he recognised causal explanations in mental illnesses; on the other he warned against believing in the ability to understand mental illnesses by brain mechanisms alone. This had implications for treatment: a reductionist, causality-driven approach to the patients could hinder the 'psyche seeking help' from participating actively in the treatment [24]. Psychiatry, according to Jaspers, needed to develop a phenomenological language, taking as its starting point the individual subjective experience in the sick person. Symptoms were not objects to be grasped; they needed to be understood and described through an emphatic listening position in the helper.

Jaspers' insights can be transferred to the therapy room today, by keeping in mind that biological insights about mental illnesses should not prevent us from approaching and meeting the person in front of us. Phenomenologicalpsychopathological description represents an alternative to an operationalist diagnostic method. This approach is fundamentally person-centred, since the individual's narrative and the way of presenting herself or himself - the being-in-the-world - is in focus. For the helper, that implies actively dispensing with the thought that 'this is just the disease talking'. Explanations need to be made understandable. They are saturated by meaning. The explanations need to be "hooked onto" the life of the individual.

This does not mean that generalisations are impossible or that group-level data are worthless. According to the phenomenological psychiatric tradition, certain delimitable aspects are central. First, typify the clinical picture - the patient is this or that way (aggressive, retracted etc.). She or he fills a gestalt or prototype. Second, search for consistent variables. What makes a phenomenon what it is? Which part of a symptom cannot be removed without it stopping being that particular symptom? Third, explore subjective structures, not only their meaning, but also their form (intentionality, temporal and spatial elements of experiences, inter-subjectivity etc.) [39]. In this personcentred approach subjectivity and individual interpretative perspectives are honoured.

In hallucinations, for instance, a signal appearing in the brain can lead to unusual, incoherent, pre-linguistic mental experiences. The neurotransmitter dopamine mediates the signal into interesting and attractive or repelling or threatening mental experiences. Hence, dopamine connects external stimuli and inner embodied experiences mediated through the mesolimbic pathway in the brain (attribution of salience-theory) [40,41]. The incoherent experience is then compared to familiar templates, prototypes or gestalts available to the individual. In this model, it becomes clear that the person is not a relay station between the brain and the symptom. Rather, the person is taking active part in shaping the symptoms in which the person's former experiences and history, ability to introspection, intelligence, family relations, educational level, cultural factors etc. all play a role. Humans are self-interpreting animals, as Charles Taylor has put it. Language is constitutive for our self-understanding, and our actions are value-laden, historically-situated and culturally-coloured
[42]. We constantly work to understand and verbalise our experiences and, in this process, we search for comparable mental templates, prototypes and gestalts when we try to understand new or threatening information or signals. If those templates are lacking, we might search in culture or history to make the experiences understandable and linguistically accessible and expressible [14,43]. The same theory is applicable on different states of mind, for instance feeling depressed, anxious, restless or paranoid, or when hearing voices.

\section{Specific embodied experience}

In Maurice Merleau-Ponty's thinking, being-in-the-world is characterised by a specific embodied experience [44]. Feelings, thoughts and inner experiences are not something taking place "within us". Rather, they are fundamentally relational phenomenon which involve objects, other living beings, cultures and institutions [33]. Mental experiences and symptoms - cannot be separated from the world or the objects around us. We are situated and localised in contexts which are constitutive for our existence. This makes our consciousness not only embodied but also situational (attached to a specific interpretation of the existence we inhabit), expanded (it transcends the body and is constituted by external factors like society and technology) and dependant on interactions between autonomous systems and the environments we inhabit [20]. Consciousness cannot exist without a brain, but to limit consciousness to being a brain phenomenon is reductionist, because a myriad of brain processes are products of an interplay between the body, external stimuli, and the brain. The central nervous system is plastic, meaning that it is suggestible to and interacts with external and internal stimuli [45]. Subjectivity cannot be reduced to an epiphenomenon or an underlying neurophysiological correlate. It is precisely through our consciousness we are able to engage with the world. Take blushing as an example. Blushing and a feeling of shame can be described in physiological terms (a shameful situation leads to firing in neurons in the limbic system in the brain, increases perfusion of the vessels in the cheeks etc.), but that does not explain why one feels shame in the first place: the subjective is social and the social is subjective [46]. We carry with us biological inscriptions shaped by our relations and experiences, our history. The feeling of shame can only be understood contextually. The mental and the physiological cannot be separated into distinguishable, independent causal variables. Rather we must strive to integrate them into an understanding of an embodied self.

A phenomenological approach to mental processes departs from simplistic, causal explanatory models. Rather, description, explanation and understanding are inseparable. The individual experience of time, space, causality, individuality, and self-esteem, are intertwined with the individual's history and experiences and represent possible entrance points for understanding the person's actions, feelings, and mental processes. The therapist's goal is to 
try to 'capture' the motivational relationships making the person's consciousness and experiences coherent.

This approach turns a biologising or essentialising diagnostic model fully upside down: the individual experience is the terrain - symptoms are products of threatening information which the person struggles to make meaningful. The terrain gets priority to the map. That leaves room for the individual: the symptoms are not drained of meaning. A dimension of meaning is preserved since the symptoms are not detached from the person's creativity, subjectivity or inner life.

\section{Conclusion}

In my opinion, phenomenological psychopathology represents a productive way of thinking about illness as relational problems (in the word's broadest sense, where relational problems do not equate "conflicts") and disturbed ways of being-in-the-world. Phenomenology does not overlook biological mechanisms involved in mental illness, nor reduces phenomena to neurobiological substrates. Phenomenology represents a therapeutic method and position from which the helper can approach the patient in a listening, empathic manner. I would argue, however, that phenomenology is not radical enough in its dualist criticism; we need epistemological tools that make us capable of avoiding traditional dichotomies such as nature versus culture, brain versus mind, somatic versus mental. Phenomenology does not provide instruments for analysing power-knowledge relations and how they affect not only our perceptions of the body, but the bodily matters themselves. In phenomenological accounts, objects - and matter - tend to be taken for granted as passive and stable, even though the situatedness of relations between "us" and objects in space and time are underlined.

Discursive practices have bodily effects. Michel Foucault wrote that our bodies 'are totally imprinted by history' [47], and he aimed to show how biology and history are co-constituted in his analysis of power. Karen Barad has pointed out, however, that Foucault did not explain how these processes are enacted [48]. The diagnostic categories are not only historically dependent: it is well known that many diagnostic criteria were settled through negotiations in expert groups. But that does not explain how matter itself - biology - is materialised in historical and technoscientific practices. These questions have been thoroughly analysed in feminist writings, and one of the most prominent critics of nature/culture dichotomies in feminist science studies is Donna Haraway. According to her, bodies cannot be "taken for granted" as stable, natural, essential objects. Rather, they materialise in social interactions (e.g., language, culture, practises) [49,50].

Barad has argued that practices of knowing are themselves material engagements which configure and stabilise the world. Matter and meaning are not only intertwined, which would presuppose that they are independent and separable entities. For Barad, objectivity is about being accountable to the materialisations that we are part of. Objectivity is not possible without paying attention to how our engagements with the world, through our scientific practices, themselves are entangled in the materiality under study [48], hence the term materialsemiotics. Our interventions in nature, in medicine, in mental illness produce and enact bodies and diseases. As already mentioned, antipsychotics were important in stabilising the dopamine hypothesis of schizophrenia. Antipsychotics have thus produced one kind of mental illness, one materiality. Functional MRI produces different kinds of illnesses. Medical or scientific investigations and interventions in the body or the brain, for instance through fMRI scans, the deciphering of the genome, or the analysis of microbial gut-brain interactions, not only represent the body differently. Rather, technoscientific practices enact matter - the body, the brain and mental illness - in different ways.

We have long traditions in Euro-American culture of separating facts and the objectivity belonging to science from meaning, culture, Society and subjectivity, belonging to the social sciences and humanities [35]. But this paradigm, when applied to psychiatry, must fail because the object under study - the subjective object, the sick person - cannot be grasped if meaning is detached from matter. The position that objectivity needs to be rid of the subjective is in psychiatry founded on a false premise. Psychiatric practise, like diagnostics, is in nature valueladen because it is about promoting the human good [51]. Thus, acknowledging the ethical basis for all psychiatric epistemology is neither advocating for "relativism" nor "perspectivism", it is simply accounting for its fundamental basis. A psychiatry stripped of subjectivity is the opposite of objective, because the subjective is a substantial part of the matter in question. Genetics and epigenetics, and the multidisciplinary field called PNEI (Psycho-Neuro-Endocrine-Immunology) have provided an increasing body of evidence for how bodily matters are saturated with meaning [35,52-53]; our biology and "the environment" are entangled. Other examples are the realisation that the intra-uterine environment provokes epigenetic changes which are related to newborn neurobehaviour [54], and how psychotherapy promotes functional brain changes (neuroplasticity) [55].

Through our interventions, whether they are in research or in the clinic, we make ethical considerations and deal with ethical matters. Our interventions in nature, the kinds of illness we produce through our research practices through questionnaires, genome wide analysis, functional MRIs - are always also political. Therefore, ethics cannot be separated from epistemology and ontology. As Annemari Mol rightly points out, if matter - ontology - is only taken to 'be stable and singular, it may either be within reach or out of reach, but good and bad have nothing to do with it' [56]. If we, on the other hand, regard ontologies as less stable and as plural, as opposed to singular, the political and ethical aspects of practices scientific or therapeutic - take shape. An epistemology for psychiatry which truly pays attention to the individual - a person-centred approach - cannot, in my opinion, run away from these questions. There are promising attempts at rethinking epistemology in medicine and psychiatry, for instance the forementioned network model for disease. However, it is crucial that a new epistemology for 
psychiatry sincerely pays attention to the dichotomising practices that have truly haunted the field for so long. The biopsychosocial (or "biosocial") model runs the risk of stabilising, rather than deconstructing, dichotomies between "nature”, "culture” and "society" [3]. Reorienting psychiatry as "relational medicine" [57] could represent a beginning of a truly integrative approach where the social is biological and the biological social.

\section{Acknowledgements and Conflicts of Interest}

This paper reproduces Chapter 26 [a] of a forthcoming volume which is being serialised in the Journal in advance of the publication of the book itself in late 2020. For details see [b]. [a] Slagstad, K. (2020). Meaning and Matter in Psychiatry: A Historical View and New Approach. In: Person Centered Care: Advanced Philosophical Perspectives. Loughlin, M. \& Miles, A. (Eds.), pp. 379-391. London: Aesculapius Medical Press. [b] Asbridge, J.E. (2020). Progress in the conceptual understanding of person-centered health and social care. "Person Centered Care: Advanced Philosophical Perspectives”. Loughlin, M. \& Miles, A. (Eds.). London. Aesculapius Medical Press. European Journal for Person Centered Healthcare 8 (1) 17-19. I would like to thank Anna Luise Kirkengen for generous feedback on an early draft of this paper. The author reports no conflicts of interest.

\section{References}

[1] Pickstone, J.V. (2001). Ways of Knowing: A New History of Science, Technology and Medicine. Chicago: Chicago University Press.

[2] Lawrence, C. \& Weisz, G. (Eds). (1998). Greater Than the Parts: Holism in Biomedicine, 1920-1950. Oxford: Oxford University Press.

[3] Greene, J.A. \& Loscalzo, J. (2017). Putting the Patient Back Together - Social Medicine, Network Medicine, and the Limits of Reductionism. New England Journal of Medicine 377, 2493-2499.

[4] Keating, P. \& Cambrioso, A. (2003). Biomedical platforms : realigning the normal and the pathological in late-twentieth-century medicine. Cambridge: MIT Press.

[5] Priebe, S., Burns, T. \& Craig, T.K.J. (2013). The future of academic psychiatry may be social. British Journal of Psychiatry 202, 319-320.

[6] Poland, J. \& Tekin, S. (2017). Extraordinary Science and Psychiatry: Responses to the Crisis in Mental Health Research. Cambridge, Massachusetts. London, England: The MIT Press.

[7] Kapur, S., Phillips, A.G. \& Insel, T.R. (2012). Why has it taken so long for biological psychiatry to develop clinical tests and what to do about it? Molecular Psychiatry 17 (12) 1174-1179.
[8] Kendler, K.S. (2012). The dappled nature of causes of psychiatric illness: replacing the organicfunctional/hardware-software dichotomy with empirically based pluralism. Molecular Psychiatry 17 (4) 377-388.

[9] Engel, G.L. (1977). The need for a new medical model: a challenge for biomedicine. Science 196 (4286) 129-136.

[10] Kleinman, A. (1988). The illness narratives: suffering, healing, and the human condition. New York: Basic Books.

[11] Heinz, A. (1015). Der Begriff der psychischen Krankheit. Berlin: Suhrkamp.

[12] Walter, H. (2013). The third wave of biological psychiatry. Frontiers in Psychology 4, 582.

[13] Foucault, M. (2006). History of Madness. London: Routledge.

[14] Berrios, G.E. (2014). History and epistemology of psychopathology. In: Philosophical issues in psychiatry III. Kendler, K. \& Parnas, J. (Eds). Oxford: Oxford University Press.

[15] Greene, J.A. (2007). Prescribing by numbers: drugs and the definition of disease. Baltimore: Johns Hopkins University Press.

[16] Healy, D. (2002). The Creation of Psychopharmacology. Cambridge, Massachusetts: Harvard University Press.

[17] Kendler, K.S. (2015). The dopamine hypothesis of schizophrenia: an updated perspective. In: Philosophical issues in psychiatry III. Kendler, K.S. \& Parnas, J. (Eds), pp. 283-294. Oxford: Oxford University Press.

[18] Licinio, J. (1996). Molecular Psychiatry: the integration of molecular medicine and clinical psychiatry. Molecular Psychiatry 1996; 1 (1) 1-3.

[19] Sotelo, J.L. \& Nemeroff, C.B. (2017). Personalized medicine in psychiatry Depression as a systemic disease. Personalized Medicine in Psychiatry 1-2, 11-25.

[20] Malt, E.A., Juhasz, K., Malt, U.F., et al. A Role for the Transcription Factor Nk2 Homeobox 1 in Schizophrenia: Convergent Evidence from Animal and Human Studies. Frontiers in Behavioral Neuroscience 10, 59.

[21] Parnas, J. \& Bovet, P. (2015). Psychiatry made easy: operation(al)ism and some of its consequences. In: Philosophical Issues in Psychiatry III. Kendler, K.S. \& Parnes, J. (Eds). Oxford: Oxford University Press.

[22] Hyman, S.E. (2011). Diagnosing the DSM: Diagnostic Classification Needs Fundamental Reform. Cerebrum: The Dana Forum Brain Science 2011, 6.

[23] Parnas, J. \& Gallagher, S. (2015). Phenomenology and the Interpretation of Psychopathological Experience. In: Re-Visioning Psychiatry: Cultural Phenomenology, Critical Neuroscience, and Global Mental Health. Kirmayer, L.J., Lemelson, R. \& Cummings, C.A. (Eds). Cambridge: Cambridge University Press.

[24] Kirkengen, A.L. (2001). Inscribed bodies: Health impact of childhood sexual abuse. Dordrecht: Kluwer.

[25] Fuchs, T. (2014). Brain Mythologies. In: Karl Jaspers’ Philosophy and Psychopathology, pp. 75-84. New York, NY: Springer New York.

[26] Wigman, J.T.W., van Os, J., Borsboom, D., Wardenaar, K.J., Epskamp, S., Klippel, A., MERGE, Viechtbauer, W., Myin-Germeys, I. 
\& Wichers, M. (2015). Exploring the underlying structure of mental disorders: cross-diagnostic differences and similarities from a network perspective using both a topdown and a bottom-up approach. Psychological Medicine 45 (11) 2375-2387.

[27] Borsboom, D. (2017). A network theory of mental disorders. World Psychiatry 16, 5-13.

[28] Silbersweig, D. \& Loscalzo, J. (2017). Precision psychiatry meets network medicine: Network psychiatry. JAMA Psychiatry 74, 665-666.

[29] Parnas, J. (2014). The RDoC program: psychiatry without psyche? World Psychiatry 13, 46-47.

[30] Gadamer, H-G. (1975). Wahrheit und Methode. Tübingen: J.C.B Mohr.

[31] Taylor, C. (2002). The Cambridge Companion to Gadamer. In: Cambridge Companion to Gadamer. Dostal, R.J. (Ed). Cambridge: Cambridge University Press.

[32] Fricker, M. (2007). Epistemic injustice: power and the ethics of knowing. Oxford: Oxford University Press.

[33] Matthews, E. (2007). Body-subjects and disordered minds. Oxford: Oxford University Press.

[34] Kerry, R., Eriksen, T.E., Lie, S.A.N., Mumford, S.D. \& Anjum, R.L. (2012). Causation and evidence-based practice: an ontological review. Journal of Evaluation in Clinical Practice 18 (5) 1006-1012.

[35] Kirkengen, A.L., Ekeland, T., Getz, L., Hetlevik, I., Schei, E., Ulvestad, E. \& Vetlesen, A.J. (2016). Medicine's perception of reality - a split picture: critical reflections on apparent anomalies within the biomedical theory of science. Journal of Evaluation in Clinical Practice 22 (4) 496-501.

[36] Andreasen, N.C. (2007). DSM and the death of phenomenology in America: an example of unintended consequences. Schizophrenia Bulletin 33, 108-112.

[37] Marková, I.S. \& Berrios, G.E. (2012). Epistemology of Psychiatry. Psychopathology 45, 220-227.

[38] Jaspers, K. (1923). Allgemeine Psychopathologie für Studierende, Ärzte und Psychologen. 3rd edn. Berlin, Heidelberg: Springer Verlag.

[39] Parnas, J. \& Sass, L.A. (2008). Varieties of Phenomenology. On Description, Understanding, and Explanation. In: Philosophical Issues in Psychiatry: Explanation, Phenomenology, and Nosology. Kendler, K.S. \& Parnas, J. (Eds). Baltimore: Johns Hopkins University Press.

[40] Kapur, S. (2003). Psychosis as a state of aberrant salience: A framework linking biology, phenomenology, and pharmacology in schizophrenia. American Journal of Psychiatry 160, 13-23.

[41] Heinz, A. \& Schlagenhauf, F. (2010). Dopaminergic Dysfunction in Schizophrenia: Salience Attribution Revisited. Schizophrenia Bulletin 36, 472-485.

[42] Taylor, C. (1989). Sources of the self: the making of the modern identity. Cambridge: Cambridge University Press.

[43] Berrios GE, Marková IS. Toward a New Epistemology of Psychiatry. In: Kirmayer LJ, Lemelson R, Cummings CA (eds) Re-Visioning Psychiatry. Cambridge: Cambridge University Press; 2015

[44] Merleau-Ponty, M. (1962). Phenomenology of Perception. New York: Routledge.
[45] Fuchs, T. (2011). The Brain - A Mediating Organ. Journal of Consciousness Studies 18 (7-8) 196-221.

[46] Kleinman, A. \& Fitz-Henry, E. (2007). Experiential Basis of Subjectivity. In: Subjectivity. Biehl, J., Good, B. \& Kleinman, A. (Eds). Berkely: University of California Press.

[47] Foucault, M..(1977). Nietzsche, Genealogy, History. In: Language, Counter-Memory, Practice: Selected Essays and Interviews. Bouchard, D.F. (Ed.). Ithaca: Cornell University Press.

[48] Barad, K. (2007). Meeting the universe halfway: quantum physics and the entanglement of matter and meaning. Durham: Duke University Press.

[49] Haraway, D. (1991). Situated Knowledges: The Science Question in Feminism and the Privilege of Partial Perspective. In: Simians, Cyborgs, and Women: The Reinvention of Nature, pp. 183-201. New York: Routledge.

[50] Haraway, D. (2003). The Promises of Monsters: A Regenerative Politics for Inappropriate/d Others. In: The Haraway Reader, pp. 63-124. New York: Routledge.

[51] Loughlin, M. \& Miles, A. (2015). Psychiatry, objectivity, and realism about value. In: Alternative perspectives on psychiatric validation : DSM, IDC, RDoC, and Beyond. Zachar, P., St. Stoyanov, D., Aragona, M. \& Jablensky, A. (Eds.), pp. 146-163. Oxford: Oxford University Press.

[52] Kirkengen, A.L. (2018). From wholes to fragments to wholes-what gets lost in translation? Journal of Evaluation in Clinical Practice 24 (5) 1145-1149.

[53] Kular, L. \& Kular, S. (2018). Epigenetics applied to psychiatry: Clinical opportunities and future challenges. Psychiatry and Clinical Neurosciences 72, 195-211.

[54] Lester, B.M., Conradt, E. \& Marsit, C.J. (2014). Are epigenetic changes in the intrauterine environment related to newborn neurobehavior? Epigenomics 6, 175-178.

[55] Barsaglini, A., Sartori, G., Benetti, S., Pettersson-Yeo, W. \& Mechelli, A. (2014). The effects of psychotherapy on brain function: A systematic and critical review. Progress in Neurobiology 114, 1-14.

[56] Mol, A. (2013). Mind your plate! The ontonorms of Dutch dieting. Social Studies of Science 43, 379-396.

[57] Fuchs, T. (2017). Zwischen Psyche und Gehirn. Nervenarzt 88, 520-528. 